\title{
Muscle invasive bladder cancer culminating with leptomeningeal carcinomatosis
}

\author{
Tom W. Swallow, MD; Scott Mabbutt, MD; Charles R.W. Bell, MD
}

Urology Department, Northampton General Hospital, U.K.

Cite as: Can Urol Assoc J 2015;9(11-12):E903-4. http://dx.doi.org/10.5489/cuai.3185 Published online December 14, 2015.

\section{Abstract}

This case reports highlights a rare metastatic manifestation of transitional cell carcinoma of the bladder. The onset of symptoms associated with meningeal irritation should be investigated. However, there is little consensus in the treatment of leptomeningeal carcinomatosis and it should be considered a poor prognostic sign with symptomatic management.

\section{Case report}

A 51-year-old woman with a history of G3 pT4 transitional carcinoma of the bladder previously treated with chemoradiotherapy, was admitted to hospital after feeling generally unwell for three days. Her recent history included deteriorating renal function associated with bilateral hydronephrosis managed with indwelling bilateral ureteric stents. No evidence of local tumour recurrence within the bladder was found at cystoscopy.

Initial investigations showed an acute kidney injury with a creatinine of $822 \mu \mathrm{mol} / \mathrm{L}$ from a baseline of 190-200 $\mu \mathrm{mol} / \mathrm{L}$. She had bilateral loin tenderness. She was catheterized and placed on strict fluid balance. An urgent ultrasound scan showed bilateral hydronephrosis. She was scheduled for an urgent cystoscopy and stent change.

On induction of anesthesia, the patient suffered a grand mal seizure that self-terminated after less than five minutes. The procedure went ahead and both stents were successfully replaced. Postoperatively, the patient was taken to intensive care for hemofiltration and ventilation. An immediate postoperative computed tomography (CT) scan of the head was reported as normal. Her postoperative urine output was adequate, but she was slow to wean.

She was stepped down to the ward on Day 7 post-admission and she started complaining of photophobia and neck stiffness. However, there were no other focal neurological signs and a medical review felt that meningitis was unlikely.
Day 10 post-admission, the patient experienced left arm weakness that resolved on its own within an hour.

In view of the clinical picture, a neurology opinion was sought. Magnetic resonance imaging (MRI) scan of the brain and a lumbar puncture was recommended. The MRI report suggested that appearances are highly suspicious of a meningeal pathology, either infection or metastatic disease. MRI with contrast was organized the next day to help differentiate between the two (Fig.1). The report concluded that the images are consistent with leptomeningeal carcinomatosis with mild hydrocephalus (Fig. 2).

The results of the cerebral spinal fluid analysis were inconclusive; no malignant cells were found on cytology and there was no evidence of infection or xanthochromia.

The patient was started on dexamethasone $8 \mathrm{mg}$. After discussion among the local multidisciplinary team, she was referred to the palliative care team for further care. She was discharged to the local hospice and died eight days later of metastatic cancer.

\section{Discussion}

Bladder cancer is the ninth most common cancer diagnosis worldwide, with more than 330000 new cases each year and more than 130000 deaths per year. ${ }^{1}$ The most common sites for metastatic spread are lymphatics and lungs. The European Association of Urology (EAU) recommends CT and MRI as the diagnostic techniques of choice to detect metastases. Metastases to bones or brain at the presentation of invasive bladder cancer are uncommon. A bone scan and additional brain imaging are, therefore, not routinely indicated unless the patient has specific symptoms or signs to suggest bone or brain metastases. ${ }^{2,3}$

Meningeal carcinomatosis (MC) is rare and occurs in $1-18 \%$ of patients with solid tumours, most commonly carcinomas of the breast and lung or melanomas. ${ }^{4}$ There have only been a few reported cases of MC associated with transitional cell carcinoma of the bladder. Furthermore the number of MC being an isolated metastasis is extremely uncommon. 


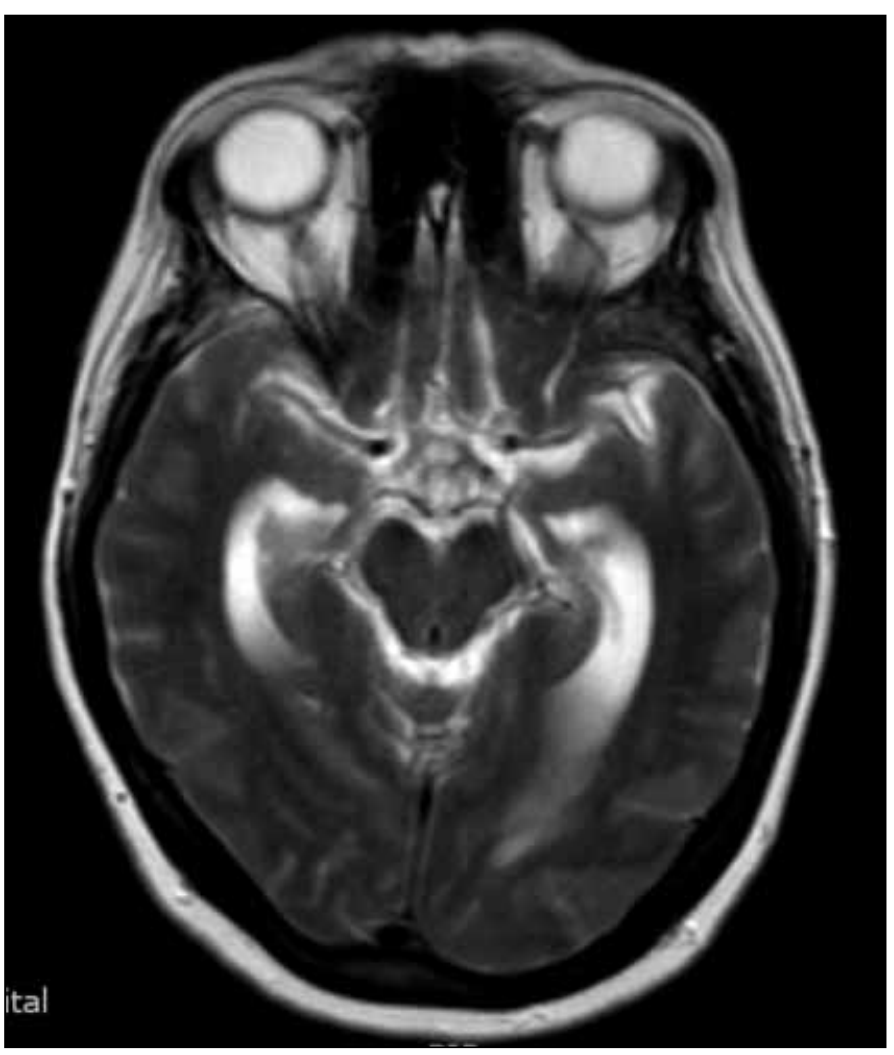

Fig 1. Dilated ventricles.

Although rare, there have been suggestions that $\mathrm{MC}$ and central nervous system (CNS) spread may be associated with chemotherapy. With prolonged survival, intraparenchymal brain metastases may occur in as many as $12 \%$ of patients who received methotrexate, vinblastine, doxorubicin, and cisplatin (M-VAC) chemotherapy. ${ }^{5}$ In the series by Bishop et al, ${ }^{6}$ two of 17 patients treated with MVAC had carcinomatous meningitis.

One thing that is clear from the isolated case reports is that the prognosis in those patients with $M C$ is very poor. One of the more comprehensive reviews confirms poor prognosis, with an average survival of 2.2 months for all patients in which survival has been reported. ${ }^{6}$

If $\mathrm{MC}$ is suspected, then the key investigation is gadolinium-enhanced MRI. Lumbar puncture may help in achieving a cytological diagnosis, but may not give any further information.

There is no real consensus as how to treat these patients. Some centres have tried intrathecal chemotherapy and others have reported success with whole brain irradiation. ${ }^{6}$ Given the poor prognosis, symptomatic management is probably the most appropriate.

\section{Conclusion}

This case reports highlights a rare metastatic presentation of a common urological neoplasm. Meningeal-type symptoms

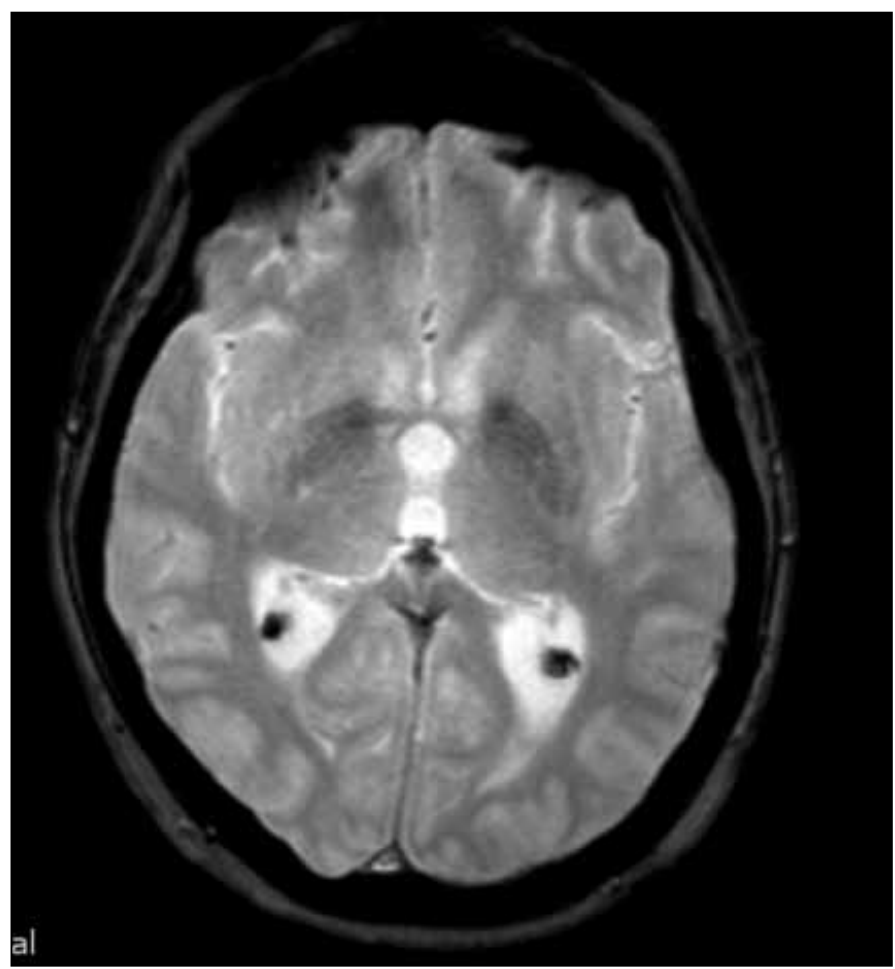

Fig 2. Abnormal meningeal enhancement.

in patients with muscle invasive bladder cancer should alert physicians to MC, although the sequalae is invariably poor.

Competing interests: The authors declare no competing financial or personal interests.

This paper has been peer-reviewed.

\section{References}

1. Wijies JA, Compérat E, Cowan NC, et al. EAU 2015 guidelines on muscle-invasive and metastatic bladder cancer. http://uroweb.org/wp-content/uploads/07-Muscle-Invasive-BC_LR.pdf. Accessed Dec. 3, 2015.

2. Braendengen $M$, Winderen $M$, Fosså $S D$. Clinical significance of routine pre-cystectomy bone scans in patients with muscle-invasive bladder cancer. Br J Urol 1996;77:36-40. http://dx.doi.org/10.1046/ j.1464-410X.1996.08467.x

3. Brismar J, Gustafson T. Bone scintigraphy in staging bladder carcinoma. Acta Radiol 1988;29:251-2. http://dx.doi.org/10.1177/028418518802900223

4. Wasserstrom WR, Glass JP, Posner JB. Diagnosis and treatment of leptomeningeal metastases from solid tumours: Experience with 90 patients. Cancer 1982;49:759-72. http://dx.doi.org/10.1002/10970142(19820215) 49:4<759::AID-CNCR2820490427>3.0.C0;2-7

5. Eng C, Cunningham D, Quade BJ, et al. Meningeal carcinomatosis from transitional cell carcinoma of the bladder. Cancer 1993;72:553-7. http://dx.doi.org/10.1002/1097-0142(19930715)72:2<553::AlDCNCR2820720236>3.0.C0;2-2

6. Bishop JR Jr, Moul JW, Maldonado L, et al. Transitional cell carcinomatous meningitis after M-VAC (methotrexate, vinblastine, doxorubicin, and cisplatin) chemotherapy. Urology 1990;36:373-7. http:// dx.doi.org/10.1016/0090-4295(90)80253-J

7. Tadepalli S, Coleman T, Hacket LA, et al. Carcinomatous meningitis: The natural history of successfully treated metastatic bladder cancer. Case Rep Oncol 2011;4:406-12. http://dx.doi.org/10.1159/000331263

Correspondence: Dr. Tom Swallow, Urology Department, Northampton General Hospital, U.K.; tomswallow@doctors.org.uk 